\title{
Margareta Niculescu: percurso e ideias sobre a formação profissional do marionetista
}

Margareta Niculescu: course and ideas on the professional training of the puppeteer

Valmor Níni Beltrame ${ }^{1}$ 


\section{Resumo}

O texto apresenta o percurso profissional e artístico da diretora teatral e pedagoga de teatro, Margareta Nicules$\mathrm{cu}$, evidenciando suas ideias em torno da formação profissional do artista no teatro de marionetes. Destaca-se seu trabalho para a superação do diletantismo, do empirismo e dos riscos da formação fundamentada somente na prática. $E$ considerada uma das mais importantes personalidades do Teatro de Marionetes da Europa no século XX.

Palavras-chave: Teatro de Marionetes; Formação Profissional; Margareta Niculescu

\section{Abstract}

The text presents the professional and artistic career of the theatrical director and pedagogue of the theater, Margareta Niculescu, evidencing his ideas about the professional formation of the artist in the puppet theater. It highlights his work to overcome dilettantism, empiricism and the risks of training grounded only in practice. And considered one of the most important personalities of the Puppet Theater of Europe in the twentieth century.

Keywords: Puppetry; professional training; Margareta Niculescu 
O futuro do Teatro pode nascer também nos canteiros de obras de uma escola.

(Margareta Niculescu)

lasi, Romênia, 1926. A cidade onde nasceu Margareta Niculescu, é conhecida com o capital cultural do país, ou como "diamante romeno", por seu patrimônio arquitetônico e cultural preservado, sua produção artística e, por ser uma cidade universitária.

$\mathrm{Na}$ época, lasi tinha cerca de 100 mil habitantes e ali, Margareta aprendeu violão e frequentava o Teatro Nacional. No início da Segunda Guerra, com 14 anos, se engaja na resistência antifascista. Depois da morte de seu pai, com 16 anos, e em plena guerra, se transfere para Bucarest, para estudar e frequenta ITCT - Instituto de Arte Teatral e Cinema (Niculescu, 2015, p. 385).

Formada em direção teatral, dirigiu o Teatro Tandarica entre os anos de 1949 e 1986, recebendo diversos prêmios nacionais e internacionais pelos espetáculos dirigidos na Romênia e em outros países como Alemanha, Sérvia, Bélgica, Egito, França, Bulgária, Noruega.

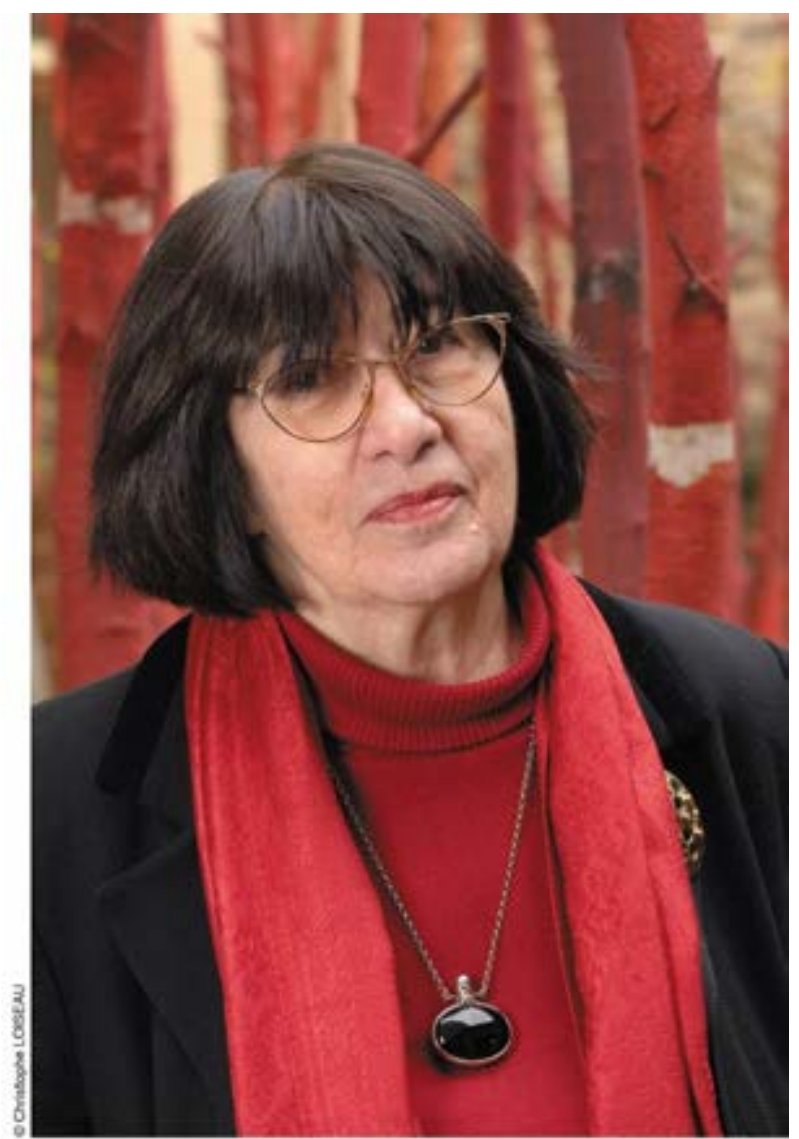

Margareta Niculescu. Foto de Christophe Loiseau

Criou e dirige o Studio do Marionetista, em 1976, e ali trabalha na perspectiva da formação do artista do teatro de marionetes ${ }^{2}$ como ator-animador, superando visões conservadoras e reducionistas desta arte. Integra o Comitê Executivo da

\footnotetext{
2 Uso as expressões "marionetes" e "marionetistas" por serem as formas correntes em língua francesa para designar o que no Brasil denominamos bonequeiros, titeriteiros, marionetistas, e atores do Teatro de Animação, teatro de formas animadas, teatro de bonecos, teatro de objetos e as outras modalidades que integram este campo teatral.
} 
UNIMA - Union Internationale de la Marionnette, desde 1957 e presidiu a Comissão de Formação Profissional desta entidade, no período de 1976 a 2000.

Em 1981, apoiou a iniciativa de Jacques Felix para criar o Institut International de la Marionnette, em Charleville-Mézières (França) e em 1985 assume a sua direção. Nesta cidade, em 1987, criou a Escola Nacional Superior das Artes da Marionete ESNAM e a dirigiu até o ano de 2000 (Pepino, 2009, p. 493). Paralelamente, Margareta amplia suas atividades como diretora e pedagoga, ministra cursos e oficinas, funda as Revistas PUCK (1988) e E Pur si Muove (2002), publica textos contribuindo, desse modo, com a consolidação do teatro de marionetes como campo de criação cênico contemporâneo.

No presente texto busco apresentar o seu percurso artístico e profissional, sublinhando algumas ideias sobre formação profissional no Teatro de Marionetes que criou e defendeu.

\section{O primeiro encontro}

Conheci Margareta no ano de 1982, em Charleville-Mézières (França), por ocasião do encerramento do Estágio Internacional sobre Teatro de Sombras, coordenado por Jean Pierre Lescot, e organizado pelo Institut International de la Marionnette, instituições locais e a Comissão de Formação Profissional da UNIMA. Professores-artistas da China, Índia, Grécia e da França se revezaram com intervenções no Estágio, que teve a duração de 450 horas e, se realizou no período de 28 de junho a 24 de setembro de 1982. Na oportunidade, por ser a Presidente da Comissão de Formação Profissional da UNIMA, esteve presente no encerramento desta ação educativa que coincidiu com o início do Festival Mondial des Théâtres de Marionnettes que logo se realizaria na cidade. ${ }^{3}$

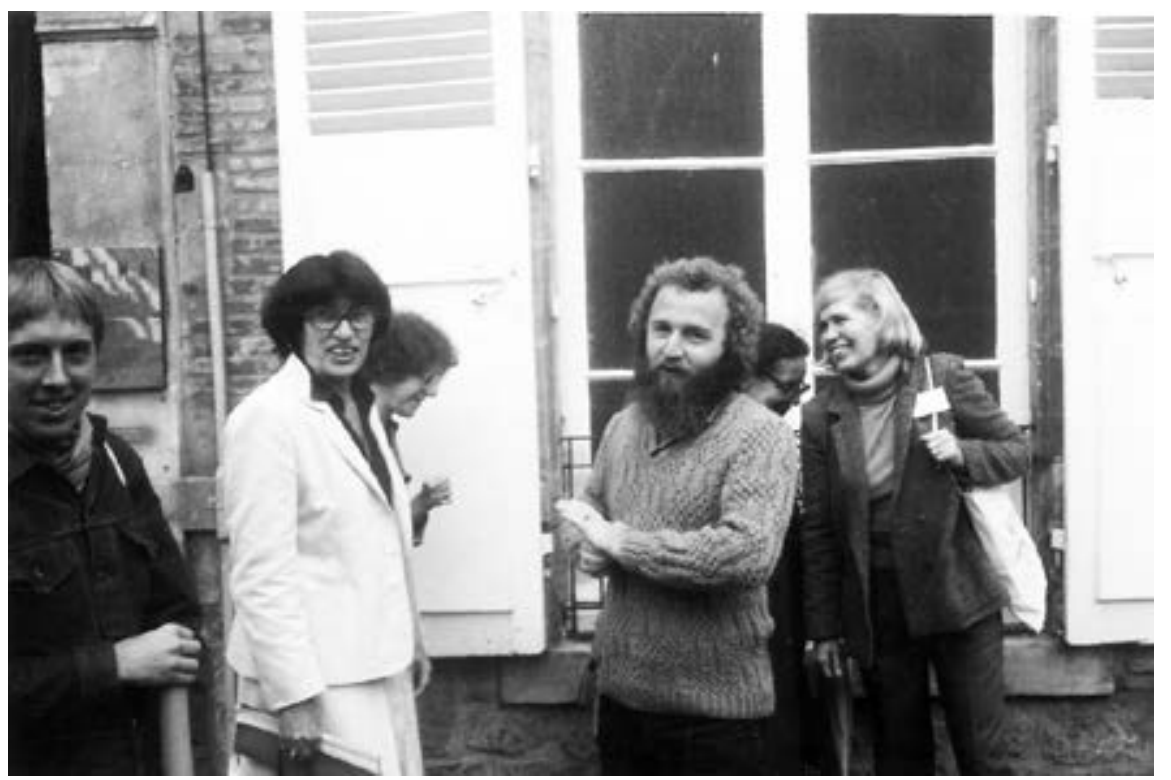

Margareta Niculesco entre os marionetistas Paul Mesner (USA), Níni Beltrame (Brasil) e Alellu Kurten (USA), durante o Festival Mondial des Théâtres de Marionnettes, de Charleville-Mézieres, 1982.

30 Festival aconteceu no período de 24 de setembro a 01 de outubro de 1982 e foi dedicado ao Teatro de Sombras. Por isso reuniu, exposições sobre o tema e o programa do evento convidou importantes grupos de teatro que trabalhavam com a linguagem da sombra. 
Convivemos durante o encerramento do Estágio, durante o Festival e lembro que ela gostava de ouvir os 13 estudantes de Teatro de Sombras, marionetistas oriundos de nove países participantes do Estágio. As perguntas que nos fazia não eram perguntas protocolares, evidenciava real interesse por nossas opiniões. Procurava falar com cada estudante, individualmente, interessada em saber o sentido daquela experiência para cada um de nós. Demonstrava gostar de conversar e ouvir as pessoas e, isso me chamou a atenção. Eu, um jovem marionetista, só comecei a compreender a importância do seu trabalho e o reconhecimento que havia conquistado em seu país, quando, ao nos despedirmos pedi o seu endereço para the escrever uma carta assim que retornasse ao Brasil. Eu gostava de escrever cartas, e vale lembrar que naquela época elas eram manuscritas. Ela me disse: basta escrever para Margareta Niculescu, Bucareste, Romênia, que chega, eu recebo. Para mim foi um susto!

Naquela ocasião e em tantas outras em que participo de Festivais de Teatro de Bonecos tenho tido a oportunidade de conhecer artistas, pessoas ligadas ao teatro de animação. Com algumas delas, logo se estabelece uma espécie de empatia, uma ligação, um sentimento e impressão de que já nos conhecíamos. Quando solicitei seu endereço, o fiz porque fui tomado por este sentimento, o de que nos encontraríamos outras vezes, porque tínhamos muito para conversar.

\section{Visitas ao Brasil}

Entre os anos de 1984 e 2004, Margareta visitou o Brasil em seis ocasiões. Descrevo rapidamente suas visitas e me atenho a sua participação no Festival Internacional de Teatro de Boneco de Canela - RS.

A primeira vinda se deu no ano de 1984, a Curitiba - PR, ocasião em que participou do Festival Nacional de Teatro de Bonecos organizado pela Associação Brasileira de Teatro de Bonecos - ABTB-UNIMA Brasil e pela Fundação Teatro Guaíra. Na oportunidade proferiu palestra no Mini auditório, o Teatro Glauco Flores de Sá Brito, em que nos falou sobre o que era a UNIMA e suas principais ações. A ABTB só passou a ser extensão, o braço da UNIMA em nosso país, no ano de 1979. Margareta abordou o tema com desenvoltura e, sobretudo com um humor desconcertante. Dissertou sobre os inúmeros limites de uma associação cultural internacional como a UNIMA e brincava dizendo que a UNIMA não possuía o orçamento e nem os poderes da ONU, mas ao mesmo tempo, demonstrava seu entusiasmo por associar-se, sobre a importância de os bonequeiros se organizarem.

Em 1987 esteve no Rio de Janeiro e em São Paulo a convite das amigas Magda Modesto (1926 - 2011) e Ana Maria Amaral. Queria conhecer melhor aspectos da cultura brasileira, como o Barroco Mineiro e por isso, também visitou as cidades históricas de Minas gerais, em especial, Ouro Preto.

A criação do Centro Latino Americano de Teatro de Animação, no ano de 1993, no Rio de Janeiro, pode ser visto como emblemática na parceria de Margareta Niculescu com o teatro de bonecos brasileiro. A iniciativa de organizar este espaço de formação e atualização profissional para titeriteiros do Brasil e da América Latina, tão sonhada por Magda Modesto, e o trabalho conjunto com Ana Pessoa e Humberto Braga, na época servidores do Ministério da Cultura do Brasil - MINC, encontrou o apoio internacional em Margareta. A sede era a antiga fazenda do diretor teatral 
e diplomata Paschoal Carlos Magno, na Aldeia de Arcozelo, na pequena cidade de Paty do Alferes, interior do Estado do Rio de Janeiro. No ano de 1994 ela retornou ao país para ministrar um estágio sobre Direção Teatral, justamente no Centro Latino Americano de Teatro de Animação, para diretores teatrais de diferentes regiões do Brasil, além de Costa Rica e Argentina. Foram 21 dias de intenso trabalho que iniciava as $08 \mathrm{~h} 00 \mathrm{~min}$ e se estendia pela noite. ${ }^{4}$

Antes disso, em 1999, no período de 22 a 30 de julho, esteve pela primeira vez na cidade de Olinda - PE, para participar da Reunião do Comitê Executivo da UNIMA e Reunião da Comissão responsável pela edição da Encyclopédie Mondiale des Arts de la Marionnette. ${ }^{5} \mathrm{Na}$ ocasião, se comemorava o aniversário de 70 anos de criação da UNIMA. O Teatro Mamulengo Só-Riso sob a coordenação de Fernando Augusto G. Santos, juntamente com a FUNARTE - Fundação Nacional da Arte representada por Humberto Braga e Ana Pessoa organizaram as Reuniões e um Festival de Teatro de Bonecos.

Sua última vinda, se deu, para participar do Festival SESI Bonecos do Mundo, de 07 a 12 de dezembro de 2004, nas cidades de Olinda e Recife - PE, convidada por Lina Rosa Vieira (Coordenadora Geral do evento) e Fernando Augusto G. Santos, responsável pela organização da etapa formativa incluindo as oficinas e conferências. Participamos de uma mesa redonda, e na plateia, cerca de 300 pessoas, sobretudo jovens artistas, ávidos por ouvi-la.

Das suas vindas e participações em Festivais no Brasil, destaco o modo como Margareta comentava os espetáculos diante dos elencos. Pude ver isso mais detalhadamente quando, em julho do no ano de 1992, acompanhou o 5을 Festival Internacional de Teatro de Bonecos realizado na cidade de Canela - RS, sob a coordenação de Antônio Carlos Sena. Sua experiência como diretora teatral a fez adquirir um olhar objetivo e preciso sobre os aspectos fundamentais da cena. Com serenidade ela apontava os aspectos relevantes e significativos do espetáculo, mas também enumerava, com detalhes, aspectos frágeis, as contradições, as inconsistências. Aprendi com ela que, o modo como a crítica é explicitada, pode dar início a um importante diálogo sobre a encenação, ou pode criar desestímulos ao elenco. A clareza e, sobretudo, o respeito e o desejo de colaborar com o crescimento do grupo de teatro caracterizam seu modo de analisar os espetáculos.

Sua curiosidade e vontade de conhecer as pessoas e grupos a levava a acompanhar a programação do Festival de Canela, principalmente os do nosso Teatro de Bonecos Tradicional Popular, o Teatro Mamulengo e o Teatro João Redondo. Estavam presentes os Mestres Chico Daniel e um dos Irmãos Relampo, do Rio Grande do Norte, que apresentaram os seus "João Redondo". Mestre Chico Daniel estava impagável com seu boneco Baltazar.

$\mathrm{Na}$ oportunidade, eu iniciava meu curso de Mestrado em Teatro, na Universidade de São Paulo. Mais uma vez, ela me chamou para conversar, queria saber o

\footnotetext{
40 Centro realizou cursos trazendo renomados diretores, além de Margareta Niculescu, em 1994; Álvaro Apocalypse (1937 - 2003$)$, diretor do Giramundo Teatro de Bonecos (Brasil) com o tema: Cenografia e Tecnologia - Espaço e Imagem, em 1994; Osvaldo Gabrieli, diretor do Grupo XPTO (Brasil) com o tema: Som, Forma, Cor e Movimento, em 1995; Fabrizio Montecchi, Antonella Enrietto e Franco Quartiere, do Teatro Gioco Vita (Itália) com o tema: Teatro de Sombras, em 1995. A partir do ano de 1996 as atividades do Centro foram interrompidas por falta de recursos financeiros.
}

5 Este importante projeto, sonho que envolveu mais de uma centena de pesquisadores de todos os continentes, foi coordenado pelo amigo de Margareta, Henryk Jurkowski (1929 - 2016) e, só se concretizou no ano de 2009 quando a Encyclopédie foi publicada, na França, pela UNIMA e pela editora L'Entretemps. 
tema da pesquisa, me estimulou falando da importância do teatro de marionetes estar presente na formação de jovens atores dentro da Universidade e me alertou para a importância de não abandonar a prática, seja a da atuação ou a da direção teatral. Com sua experiência, conhecia os benefícios, mas também os riscos que a instituição, qualquer instituição, oferece e, às vezes, impõe. Na ocasião me disse: Confio totalmente na Escola. Consciente de que se trata de uma instituição. Deve-se ter medo da palavra? Tudo depende das pessoas que a habitam e das ideias que nela circulam (Beltrame, 2001, p. 253).

Afirmou que sempre teve muito cuidado, mas nunca se amedrontou com instituições e, seu percurso demonstra que nas instituições nas quais atuou, a constituição de grupo e o compromisso com o trabalho ajudam a superar os percalços que a instituição exige. A serenidade com que falava destas preocupações me soava principalmente como alerta, uma demonstração de cuidado, própria de quem conhece os riscos para o trabalho do artista dentro de instituições.

Presenteou-me com o livro de Henryk Jurkowski, Écrivains et Marionnettes dizendo: leia este livro, é resultado de uma pesquisa cuidadosa, certamente vai te ajudar. E realmente foi importante, comecei a me interessar mais pelas ações das denominadas vanguardas históricas europeias e suas relações com o teatro de marionetes. ${ }^{6}$

Reafirmei a ideia de Margareta como uma espécie de tutora, que gosta de ajudar e de orientar profissionalmente jovens artistas.

\section{O Curso de direção teatral}

Quando participei do Curso Escritura y Dirección Teatral por ela ministrado em Sevilla (Espanha), seu peculiar modo de analisar cenas me chamou a atenção novamente. Era o ano de 1998 e, Guadalupe Tempestini, diretora do Teatro Alameda, convidou-a para ministrar o curso durante a Feira de Teatro que anualmente ela organizava na cidade, com o apoio dos governos locais e da UNIMA Federación España. Estavam reunidos marionetistas não só daquele país, como de alguns países da América Latina como: México, Argentina e Brasil. Como se tratava de um curso de direção teatral a ser ministrado num curto espaço de tempo, Margareta iniciou os trabalhos afirmando que partiria de uma dramaturgia previamente definida, porque acredita que um bom texto dramático é meio caminho andado numa encenação. Trabalhamos com textos de Federico Garcia Lorca, Samuel Beckett, Ramón del Valle-Inclán, entre outros. Eu não conhecia o texto Rosa de Papel, de Valle-Inclán e, foi para mim uma descoberta.

Trabalhei com Analía Sisamón, uma jovem titeriteira argentina, na criação de uma cena com cerca de 15 minutos que adaptamos do texto, confeccionamos os bonecos e escolhemos a cripta, uma parte do subsolo do Instituto del Teatro de Sevilla, local do Curso, para a apresentação pública do nosso trabalho. Optamos por trabalhar à luz de velas e com bonecos feitos de papel Kraft, papel de embrulho. Exploramos o volume dos narizes, com formato de bicos de corvo, utilizando o grotesco como elemento que

6 Durante os anos de 2002 a 2014 ofereci a disciplina A marionetização do ator e a humanização do objeto, no Programa de Pós-Graduação (Mestrado e Doutorado) em Teatro do Centro de Artes da UDESC. Sob diferentes enfoques, o curso estava centrado na relação da marionete e do teatro de marionetes nas ações das vanguardas históricas, no período entre o final do Século XIX até a década de 1920. O livro foi uma referência importante para o curso. 
bem caracteriza o esperpento ${ }^{7}$ proposto por Valle-Inclán. Margareta teve o cuidado de convidar um professor de estética e história do teatro, da Universidade de Sevilla, para fazer uma palestra sobre o tema, para nós participantes do curso. O esperpento nos estimulava a explorar a deformação, os excessos e o grotesco. Sua preocupação para que nos apropriássemos de conceitos, de teoria relacionada com a prática era evidente.

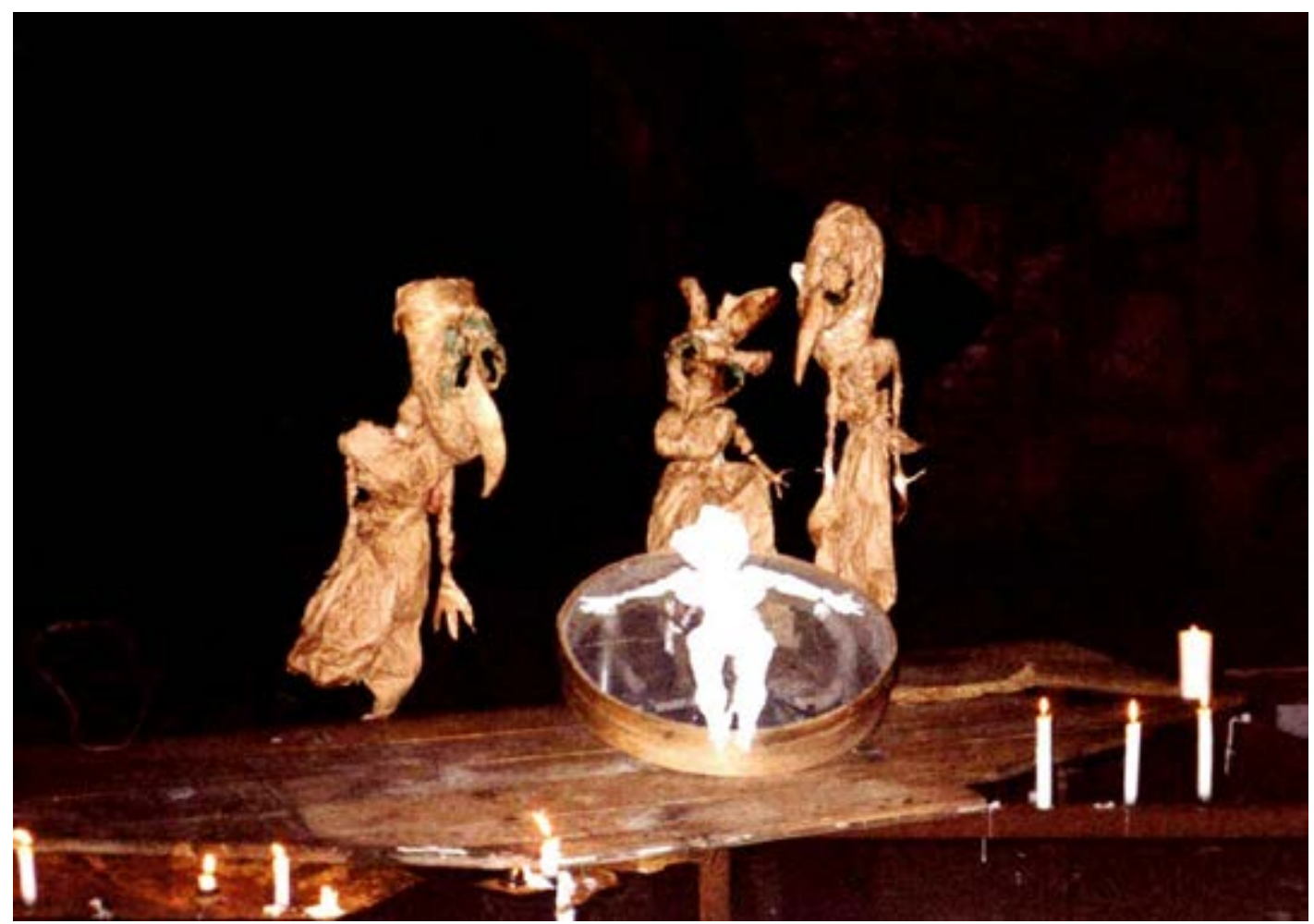

Rosa de Papel. Texto de Ramón del Vallle-Inclán. Exercício de direção teatral sob orientação de Margareta Niculescu. Instituto de Teatro, Sevilla, 1998.

Durante nossos ensaios, lembro de suas intervenções para estimular a escolha de gestos e ações dos bonecos, afirmando: este movimento é bom, mantenha isso. Ou quando percebia que o gesto ou a ação não eram adequados perguntava: porque fazes isso? Será mesmo que colabora com a cena? Seguia estimulando a busca de novos movimentos e ações para enriquecer a cena, o que evidenciava o modo peculiar de conduzir o trabalho demonstrando além de larga experiência, o conhecimento das especificidades desta arte. Nossos trabalhos em pequenos grupos eram permeados por observações que nos estimulavam a nos apropriarmos mais e mais da linguagem do teatro de marionetes e da direção do espetáculo. Ela dava ênfase à necessidade de suprimir o ilustrativo, descartar o supérfluo presente nas cenas; cuidar do olhar da marionete, construir partituras que colaboram para dar limpeza nos gestos e clareza nas ações; realizar pequenas pausas entre os movimentos colabora para torna-los claros e eficazes, além de outros aspectos relevantes ao trabalho do marionetista e do diretor de teatro. Não poupava elogios, mas não era condescendente com superficialidades.

7 Toni Rumbau assim define o esperpento proposto por Valle-Inclán: Esperpento es la necesidad de deformar previamente la imagen, la cual debe pasar por su reflejo en el espejo cóncavo, es decir, debe desdoblarse mediante un reflejo que transforma el original en un "doble automáticamente caricaturizado", bajo los efectos del cristal cóncavo. Y, una vez desdoblado y transformado, la fórmula del Esperpento enfoca la imagen para "limpiarla" y "depurarla" y conseguir así la síntesis expresiva de la "matemática perfecta" (2011, p.143). 
Eu já conhecia seu interesse e atuação no campo da formação profissional no Teatro de Títeres, mas ali percebi que Margareta sabia que, a superação de muitos problemas relativos ao reconhecimento da nossa arte, dependem do domínio que os marionetistas têm do próprio ofício. E não se trata apenas de fazer bem, mas de fazer muito bem e saber falar sobre o que faz. O ambiente de estudo e reflexão que ela imprimia envolvia a todos nós e, se os trabalhos eram árduos, pela sua intensa carga horária e nível de exigência, Margareta não descuidava de organizar no final de jornadas um lanche regado a vinho para que todos conversassem, contassem histórias e cantassem. Este pequeno, mas importante detalhe, contribuía para criar um ambiente de trabalho harmonioso e estimulante, a sua capacidade de agregar as pessoas era evidente. Uns chamam isso de liderança, outros de carisma, não sei exatamente como denominar, mas admiro sua habilidade, seu modo acolhedor de reunir jovens artistas em torno de ideias e ações.

Outro aspecto que me chamava a atenção é seu desprendimento. Ela se hospedou nas dependências do Instituto del Teatro, naturalmente um espaço adequado, justo, porém simples, despojado. Ou seja, não fez exigências para se hospedar em lugares sofisticados como é frequente entre pessoas reconhecidas, com a destacada visibilidade no meio teatral, como ela possuía. Este comportamento, que para muitos talvez não seja importante é, para mim, revelador de seu comprometimento, de seu desejo de ver ações importantes acontecerem, de trabalhar na formação de jovens marionetistas.

\section{O pensamento pedagógico}

Conheci melhor o pensamento pedagógico de Margareta quando, em 1999, solicitei uma bolsa para pesquisar na biblioteca do Institut International de la Marionnette, em Charleville-Mézières. A bolsa consistia na hospedagem na Villa d'Aubilly - Residência para Pesquisadores e Artistas/Criadores e o acesso ao acervo de Centro de Documentação do Institut. Na época, eu preparava meu doutorado em teatro, era dezembro e na cidade fazia um frio insuportável, a temperatura caiu para 13 graus abaixo de zero durante dias e em seguida nevou por uma semana. Margareta, preocupada, me perguntava se estava bem agasalhado e contava de sua infância na Romênia onde às vezes a neve se acumulava por longos períodos chegando a quase um metro de altura. Ali permaneci durante 20 dias, lendo, consultando livros e estudos sobre a nossa arte. A minha impressão sobre Margareta tutora, se confirmava. Ela manifestava constante interesse sobre o que eu estava estudando e descobrindo para o meu trabalho. Eventualmente saíamos para tomar um cafezinho e nossas conversas giravam em torno de temas como o teatro de marionetes e sobre o Brasil. Percebia seu real interesse e curiosidade sobre a cultura brasileira. Conversávamos sobre a intensidade e o volume de seu trabalho no Institut, na École Nationale Supérieure des Arts de la Marionnette - ESNAM e na edição da Revista PUCK. Dizia que preparar a Revista era fatigante, exigente. Mas ao mesmo tempo afirmava: eu sempre gostei de realizar, de fazer. Eram os últimos meses de seu trabalho na direção da École e no Institut porque se aposentaria em seguida, no ano de 2000. Seu substituto, Roman Paska, já circulava por Charleville-Mézières, se familiarizando com o seu futuro trabalho. 
Margareta me concedeu uma longa entrevista que possibilitou compreender melhor suas ideias sobre a formação do marionetista e os eixos norteadores do seu trabalho na ESNAM. ${ }^{8}$ A íntegra da entrevista pode ser lida em Beltrame, 2001, p. 251 a 261. Sintetizo, a seguir, parte da entrevista, que organizei numa sequência de 10 aspectos, indissociáveis, que considero relevantes para compreender suas ideias sobre formação no Teatro de Marionetes. Os trechos destacados em itálico são a transcrição literal de parte da entrevista.

\section{1 - Teatro de animação é teatro}

Margareta defende que o teatro de animação é antes de tudo teatro e, ao mesmo tempo, tem especificidades, uma delas consiste em animar o objeto inanimado. A escola deve oferecer uma sólida formação de ator ao mesmo tempo em que trabalha a especificidade que caracteriza o teatro de animação. Na sua perspectiva o marionetista é um ator que vive o mesmo processo do ator. Ele encontra na marionete os materiais inanimados, que podem ser bonecos articulados, antropomorfos ou não, são materiais que podem ser metamorfoseados em personagens de teatro pelo movimento. Mas em que momento o ator se transforma em marionetista ou o marionetista se ampara na suas qualidades de ator, eu penso que é um processo misterioso e muito pessoal. $E$ defendia: o interesse da escola, em minha opinião, reside em oferecer inicialmente uma formação de base idêntica à formação do ator, considerando que o marionetista é um homem de teatro.

\section{2 - Polifonia e Síntese}

O teatro de marionetes não pode estar confinado em si mesmo como linguagem artística, tem estreita relação com as outras artes e a formação do estudante marionetistas precisa contemplar o estudo e a relação com artistas que trabalham com outras linguagens. Vale destacar a forma como encaminhava tais procedimentos na ESNAM: Atualmente, as definições de teatro são imprecisas. Não existem fronteiras entre os gêneros, estilos, artes. Mais que nunca as artes da cena - e entre elas o teatro, sempre cruzado, síntese de artes - conhecem uma fisionomia imprevisível de linguagens cênicas. Os coreógrafos, músicos, trabalham os campos do ator; o homem de teatro faz, do seu modo, papel de artista plástico, de imagem ou artista visual. Penso que o mais rico e fértil, que abre perspectivas mais amplas, é quando o processo de ensino, já no princípio, oferece possibilidade de entrar no universo do ator, no universo do seu corpo, no universo plástico, no universo da criação de objetos. Penso que todas essas coisas se inter-relacionam. [...]

Eu imaginei que numa escola multidisciplinar, global, a interferência de disciplinas, o ir e vir entre técnica e criação possibilitasse um caminho sobre o qual se pode conseguir as verdadeiras respostas. É como rios paralelos que misturam suas águas. $A$ arte e a profissão não são coisas separadas. "A profissão está em permanente evolução e busca" afirmava Copeau. Estas palavras utilizadas para o teatro de ator são ainda mais verdadeiras para o teatro de marionetes diante de múltiplas técnicas. Não esqueçamos, não mais, que vivemos num tempo onde se multiplicam os vínculos entre os homens,

8 A entrevista e a concepção pedagógica da ESNAM, dirigida por Margareta está disponível nos anexos da minha tese: Beltrame, 2001 , p. 251 a 261. 
artes e culturas. Não esqueçamos, não mais, que uma escola é uma oportunidade de sair do isolamento, de se abrir às práticas artísticas vindas de outros horizontes. É sobre o percurso da escola que se podem construir as pontes entre o passado e o futuro para colocar as bases menos frágeis à uma busca individual e abrir, eventualmente, as perspectivas do futuro do teatro. Eu continuo ligada à multidisciplinaridade, à ideia de confiar a formação de jovens artistas a mestres que vêm do campo da criação, prioritariamente; à escola onde reinam o espírito de abertura, à curiosidade, à coragem do risco, à criatividade, ao rigor, aceitando as ideias mais loucas e as mais sãs. Optei pela multidisciplinaridade correndo os riscos de seus limites ou até mesmo contradições. $A$ multidisciplinaridade é uma oportunidade, a de fazer descobertas nas últimas portas recém-abertas e também ir ao encontro do desconhecido.

\section{3 - Indissociação: teoria e prática}

O conhecimento da teoria não está dissociado da prática. Na sua visão, ao mesmo tempo em que a escola oferece a maior quantidade de informações sobre história do teatro, das artes e suas teorias, também prioriza o estímulo à curiosidade, à experimentação, estabelecendo pontes entre as ideias de diretores, encenadores e teóricos contemporâneos com as práticas e experiências criadoras dos alunos. Ela insiste em que a melhor pedagogia pode ser a de provocar e entreter a curiosidade. Ensinar, sobretudo e antes de tudo, a paixão pelo teatro, a paixão de viver o imaginário. Diz ainda: a escola é o lugar de conhecer o que os outros fizeram, como fizeram, porque fizeram e utilizar isso não para repeti-los mas como base do conhecimento para se reinventar e criar outras linguagens.

\section{4 - A experimentação}

Margareta acredita que o estudante necessita exercitar sua criatividade em diferentes linguagens, e assim adquirir bases mais sólidas para fazer opções sobre o tipo de teatro que quer realizar. $O$ fazer, a experimentação, precisam ter um privilegiado espaço no cotidiano de uma escola, pois acredita que tal prática enriquece, amplia o conhecimento dos jovens marionetistas. Fazer, experimentar, é se expor, se desafiar, se encontrar como artista. E reforça a ideia de escola como laboratório: $E$ neste ambiente, o aluno, às vezes derrotado, contrariado, é alertado, incitado a reagir de maneira ativa, a se revelar, a afirmar suas opiniões e com isto a descobrir suas aptidões, sua sensibilidade, suas inclinações estéticas. Por isso, de um lado, a aprendizagem das matérias básicas, sem as quais não se supera o diletantismo. E de outro, a prática teatral a partir de pequenas cenas, realização de espetáculos observados por mestres atentos. Ateliês específicos para a arte da marionete, mas também do teatro, outros teatros, lugar de experimentação, de teste, permitindo aos alunos o desenvolvimento da sua própria identidade.

\section{5 - O Professor Artista}

Na sua visão o corpo docente deve ser formado por professores/artistas/pesquisadores. Margareta afirma que descrê na prática de professores que apenas repetem o que aprenderam há décadas. Mas alerta: ser artista renomado não significa, necessariamente, ser bom professor. No entanto, quando o artista gosta de sistematizar 
seu trabalho e dividir seu aprendizado e suas dúvidas com estudantes, este pode ser um rico momento de ensino. Quando os professores são artistas, criadores, pesquisadores, as possibilidades de criar um diálogo rico com os estudantes são maiores, porque as dúvidas não são formuladas apenas a partir dos trabalhos produzidos por outros artistas: eles próprios se questionam sobre sua criação e sua produção. Por isso, acredita que boa parte do corpo docente da Escola de Teatro não deve ser fixa, estável, mas deve haver uma constante renovação de professores. E afirma: $O$ olhar que possuo sobre teatro, sobre as artes da cena, suscitou meu forte desejo de aproximar artistas do ensino, os criadores, aqueles que por sua paixão, fizeram, e fazem com que o teatro seja vivo. Pensei em abrir as portas da escola àqueles que têm um saber a transmitir, sobretudo àqueles que têm ousado em seus questionamentos, executando seus próprios projetos com os alunos. Então chamei diretores, inclusive de teatro dramático, assim como criadores marionetistas. Convidei a intervir, criadores que defendem outra linguagem cênica, adeptos do teatro de imagem, teatro do movimento, teatro sem palavras, teatro de objetos, teatro de matéria animada. Suas experiências podem ampliar o horizonte do pensar e da prática teatral.

\section{6 - A Relação Pessoalizada}

Acredita que o ensino da arte do teatro exige relação direta, por vezes individualizada, entre professor e o jovem artista. Ainda que as bases teóricas para o domínio da profissão possam ser fundadas em princípios comuns, cada estudante possui uma experiência peculiar de mundo, fazendo com que seu tempo e modo de aprender sejam diferenciados. O processo de ensino numa escola de teatro se inviabiliza quando há número excessivo de estudantes, quando não se estabelecem relações diretas entre professor e estudante, quando as expectativas e dificuldades de cada um não são consideradas.

\section{7 - A Escola como local de produção de saberes}

O jovem vem à escola para dominar conhecimentos sistematizados. Como estudante de arte, no entanto, é, ao mesmo tempo, capaz de produzir saberes e competências a partir da sua experiência de mundo e de desafios que se impõe ou é estimulado a enfrentar. Afirma que esta é uma das questões essenciais: Ao jovem aspirante da arte da cena cabe desenvolver suas próprias aptidões criativas, sua identidade, sensibilidade, disponibilidade para rever o teatro, o espetáculo nas suas diferenças. A Escola deve estimular o estudante a ser autônomo. Ser ele mesmo, ser verdadeiro nas suas escolhas. Isso é essencial para mim. É nesta escola, numa escola multidisciplinar que ele pode descobrir a vivência do teatro, aprender o fenômeno espiritual, cultural, expressivo do teatro através da sua história. A Escola deve ser o local onde ele tem a chance de exercer, praticar a arte da cena e que isto lhe permita se descobrir. Modelar sua própria personalidade ao confrontar-se com os outros.

\section{8 - A Relação com o Público}

Outro aspecto importante se refere ao contato com o público. Ao defender que o teatro é a arte da teoria e da prática, o contato com o público, mesmo no período em que o jovem está na Escola, é fundamental. Essa proposta se concretiza com a 
apresentação das montagens teatrais feitas pelos estudantes, no final de cada etapa ou período letivo dirigidos por diretores profissionais convidados pela Escola. Mas vale destacar que desde o princípio eles criam cenas, sob a coordenação de um professor e as apresentam aos colegas. No final do curso (último ano), cada um monta seu espetáculo cumprindo um pré-requisito para sua saída da Escola. Niculescu explica: o final dos estudos, na ESNAM, está dedicado aos projetos de diplomação, o que significa a criação de espetáculos concebidos e realizados pelos estudantes. $A$ responsabilidade artística, a realização da produção é de sua total incumbência. Que fique claro que a Escola não fica só na expectativa. Não esqueçamos que a "saída" é outro momento de tensão vivido por eles e, também pela Escola, que torce solidária por um final feliz. Eles são acompanhados no desenvolvimento de sua ideia, de sua concepção artística, por um "mestre padrinho" do projeto. Ele está convidado a formular todas as questões no momento adequado, mas impedido de interferir na criação. As decisões pertencem aos estudantes e à sua visão.

Esta é considerada como uma oportunidade para confirmar, num espetáculo, sua vocação artística, seu conhecimento dos meios, suas habilidades, seu savoir-faire. Os projetos/espetáculos são apresentados à banca de diplomação na presença do público.

\section{9 - A Técnica}

A visão do ensino da técnica parte do princípio de que o desenvolvimento de uma linguagem estética está apoiado em técnicas. Questionada sobre o assunto, prefere responder com as palavras de um grande mestre: "Me permitiria citar Jim Henson, o criador do Muppets, que convidei para ministrar um curso no Institut International de la Marionnette. Perguntado sobre os segredos técnicos de suas criações, Jim não hesita em responder afirmando": a técnica não é tudo, depende de como cada um a utiliza e de quem a utiliza, porque a técnica se torna um meio de criação artística. Podemos conhecer as técnicas, mas se não existe criatividade, se não há imaginação, se não existem sonhos artísticos, é somente técnica.

\section{0 - A Formação Humanista}

Margareta defende que o estudante obtenha uma sólida formação humanista na Escola. Isso pode se concretizar de diversas maneiras, permeando as atividades que ali se desenvolvem para contribuir com uma "formação cultural ampla," conseguida com o estudo de conteúdos relativos à história do teatro, estudos sobre estética e ética, no domínio de línguas estrangeiras; na necessidade de ver, apreciar e conhecer outras manifestações teatrais e linguagens artísticas; nas discussões sobre a função social da arte. Ou seja, fica evidente a necessidade de realizar um conjunto de iniciativas para ampliar o capital cultural do estudante, dominar o ofício e estimular o seu autoconhecimento. Nessa perspectiva é visível que seu pensamento tem estreita conexão com ideias de Jacques Copeau, Giorgio Strehler, Peter Brook. ${ }^{9}$

9 Margareta publicou alguns textos que fornecem a visão de suas concepções sobre o papel da Escola, sua concepção como pedagoga do teatro e sobre 0 trabalho do marionetista. Apresento no final deste estudo a relação de textos-artigos mesmo sabendo que é incompleta, acreditando que possibilita ampliar o conhecimento sobre a formação profissional no Teatro de Marionetes. Não incluo na relação os prefácios e prólogos de sua autoria publicados nas Revistas PUCK e nas Revistas E Pur Si Muove! enquanto foi Editora Chefe destas publicações 


\section{E os questionamentos continuam...}

Suas ideias sobre formação aqui apresentadas, não se colocam como certezas e regras a serem seguidas. $O$ importante é perceber que ela segue, continuamente, com questionamentos que a acompanharam em todos os anos de trabalho e que são atuais e pertinentes: Quê escola propor, sobretudo quando o teatro reivindica a criação em todas as suas manifestações e formas? Como responder a isso considerando o vasto território das poéticas teatrais cobertas pela palavra marionetista? Que escola, para quem escolheu se expressar pela metáfora? Existe vocação para se tornar marionetista? E além disso, o que transmitir? Um professor, marcado pela originalidade de seu próprio percurso, pode ensinar generalidades? Não é próprio do criador seguir seu caminho, suas intuições, sua parte cultural, estética e ética? E acima de tudo, quem é o estudante? Na escola, como ele pode expressar suas ideias de teatro, suas concepções, suas crenças, sem oprimir a sua personalidade? (Niculescu, 2015, p.391). Essas dúvidas, e tantas outras, colaboram para embaralhar nossas certezas, nos tirar do lugar de conforto e nos estimulam a duvidar e experimentar novos caminhos para o teatro.

Margareta Niculescu é vista por muitos de nós como uma das grandes estimuladoras da formação profissional de marionetistas brasileiros. Isso se deve não só às suas intervenções diretas no Brasil, como também, e principalmente, pelas oportunidades que criou para que artistas do nosso país estudassem no Institut International de la Marionnette e na École Nationale Supérieure des Arts de la Marionnette, em Charleville-Mézières. É difícil listar com precisão todos os que participaram dos programas oferecidos na Escola e no Instituto. Certamente todos nós que por lá passamos lembramo-nos da generosidade e do carinho com que éramos recebidos por ela. No Brasil, nós marionetistas, temos um sentimento de profunda gratidão por tudo o que Margareta fez por nós e pelo teatro de marionetes do nosso país.

\section{Referências}

BELTRAME, Valmor. Animar o Inanimado: a formação profissional no teatro de bonecos. Tese (Doutorado). Escola de Comunicação e Artes. Universidade de São Paulo - USP. 2001.

NICULESCU, Irina. Margareta Niculescu - portrait em esquisses. In VAILLANT, Philippe. Figures Ardennaises. Saint Loup Terrier: Les 3 Mondes, 2017.

PEPINO, Cristian. Margareta Niculecu. In Encyclopédie Mondiale des Arts de la Marionnette. Montpellier: L'Entretemps, 2009.

RUMBAU, Toni. Valle-Inclán y la estética del Bululú. In Móin-Móin - Revista de Estudos sobre Teatro de Formas Animadas. Jaraguá do Sul: SCAR/UDESC, ano7. v.8, 2011. 


\section{Artigos publicados por Margareta Niculescu}

NICULESCU, Margareta. In VEIGA, Ribes. ELART - Associazone fra Enti Locali, Artista. Mantova: Ed. Operatori Culturali, 1993.

NICULESCU, Margareta. École de Théâtre, École de vie. In PUCK. La Marionnette et les Autres Arts - Pró-Vocation L'École. n.7. Charleville-Mézières: Institut International de la Marionnette, 1994.

NICULESCU, Margareta. L'Ecole Supérieure Nationale des Arts de la Marionnette. Charleville-Mézières: Institut International de la Marionnette, 1998.

NUCULESCU, Margareta. Reflexiones sobre la Escuela Nacional Superior de Marionetas. In La Múndia. Revista del Titella i del Teatro Animat. n.6 Valencia, 1999.

NUCULESCU, Margareta. L'avenir du théâtre peut naître aussi sur les chantiers d'une école. [O futuro do teatro pode nascer também nos canteiros de obras de uma escola.] Tradução de José Ronaldo Faleiro e Margarida Baird. In Móin-Móin - Revista de Estudos sobre Teatro de Formas Animadas N.06. Jaraguá do Sul: CEART/UDESC, 2009.

NICULESCU, Margareta et BODSON, Lucille. L'Institute International de la Marionnette. Montpellier: L'Entretemps, 2009.

NICULESCU, Margareta. Sous le signe de l'experimentation. In Passeur et cumplices - Passing it on. Montpellier: L'Entretemps et Institut International de la Marionnette, 2009.

Recebido em: 17/07/2018

Aprovado em: 17/07/2018 